\title{
Awareness and Attitude toward Infection Control among Health Care Workers during Coronavirus Disease-19 Pandemic, Egypt
}

\author{
Ahmed Yamany Ali $^{1 *}$, Abeer Attia Abdelkhalik ${ }^{2}$, Shereen Esmat ${ }^{2}$, Walaa Alsharany Abuelhamd ${ }^{3}$, Hend Abdullah Elshemy ${ }^{1}$, \\ Mervat Essam Behiry ${ }^{1}$ \\ ${ }^{1}$ Department of Internal Medicine, Faculty of Medicine, Cairo University, Cairo; ${ }^{2}$ Department of Public Health and Community \\ Medicine, Faculty of Medicine, Cairo University, Cairo, Egypt; ${ }^{3} 3$ Department of Pediatric Medicine, Faculty of Medicine, Cairo \\ University, Cairo, Egypt
}

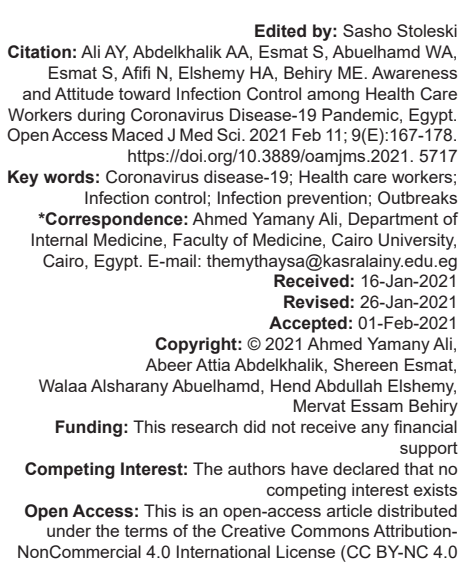

Introduction

Coronavirus pandemic is an ongoing outbreak of coronavirus disease (COVID)-19, caused by severe acute respiratory syndrome coronavirus 2 (SARS-CoV-2) [1]. Community transmission is increasing worldwide, since was first discovered in Wuhan, China, in December 2019, the WHO had announced a public health emergency event [2]. Effective infection prevention and control in healthcare facilities depends on knowledge and compliance of all health-care staffs at different levels of the health organization [3]. There is an established health policy with corroborating multidisciplinary teams accountable

\begin{abstract}
BACKGROUND: Coronavirus disease (COVID)-19 emerges worldwide consideration since their first proving. The knowledge and attitude of all
among medical institutions.

AIM: The study evaluates the knowledge of health care workers (HCWs) about infection control policies at the

a structured self-administered questionnaire that was delivered to HCWs in the selected hospitals.

A total of 486 physicians working between university, governmental, teaching, private hospitals, and polyclinics submitted their replies. Of whom, $46.9 \%$ practiced internal medicine specialty, $35.4 \%$ were pediatricians, and only $17.7 \%$ specialized in the family medicine. Regarding the overall level of knowledge about infection contro their institutions and about $79 \%$ practiced these policies while only $60.5 \%$ received some training. Furthermore, we found that $64.2 \%$ of the participant did not know which infections are officially reported. There was some variation in equipment and only $7.4 \%$ assigned the carelessness of HCWs. Moreover, the insufficient resources to fulfill the infection control requirements were assigned as a primary factor to spread of infection $(71.4 \%)$. The electronic stut revealed that there was a staticaly significant difference of knowledge of infection control among medical control toward the highly certificated individuals (having $\mathrm{PhD}$ ). Furthermore, there was a potential variance between $(p \leq 0.05)$. In addition, there was variation in responses to questions related to various institutions as a higher percent $(\mathrm{p}<0.05)$

CONCLUSION: HCWs had reasonable knowledge about infection control and surveillance during COVID-19 outbreak and we have discovered zones of concern about infection control experience in Egypt which differ between institutions and professions and years of experience.
\end{abstract}

for preparation and formalization of infection control policies and to ensure that these designs are functioning efficiently and practiced consistently among the health care workers (HCWs) to prevent and properly control COVID-19 outbreak [4].

In the context of COVID pandemic, it appeared to be the worst strike across the world with a rising curve in developed countries in spite of advanced health systems and promoted infrastructure and designs of hospital. Hence, it is expected to be of potential threat in low- and middle-income countries with poor health system delivery [5], [6] that necessitates strict measures related to infection control policy and raising the awareness on proper hygiene and social distancing [7]. 
In the term of that knowledge and attitude toward infection control and prevention is imperative for halting the outbreak, few studies had investigated the levels of infection control and prevention knowledge and practices among medical and non-medical populations across the Arabian countries [8], [9] and in Africa [10] that sharing similar socioeconomic standards and demographics as well.

Accordingly, the aim of this research is to assess the awareness of HCWs regarding infection control policy and ways among medical staff and their ability to implement and apply their knowledge in real practice and to determine the degree of their preparedness to deal with such pandemic.

\section{Methods}

\section{Study design}

This study is analytical cross-sectional survey.

\section{Study setting and population}

This study was implemented among healthcare providers including physicians and residents at governmental hospitals, private hospitals, and polyclinics, Egypt.

\section{Sampling size and type}

Non-random Snowball sampling was done through emails and social communication tools as Facebook groups and Whats -App. Using Epi-Info version 7 software, with anticipated frequency of awareness of $50 \%$ with $95 \%$ confidence interval and power $80 \%$, so the least required sample size was 384 . Considering dropouts rate of $41.8 \%$, as in the study by Galesic in 2006, therefore, the sample size was estimated to be 544 participants.

\section{Procedures of data collection}

A structured self-administered anonymous questionnaire (Appendix A) was used to collect data which derived from Rabaan et al., 2017 [11], in which a questionnaire-based analysis of infection prevention and control in health-care facilities in Saudi Arabia on Middle East respiratory syndrome (MERS) conducted. The questionnaire was administered in the English language and submitted through an electronic form and was distributed to the participants through emails and social communication tools as Facebook and WhatsApp.
The questionnaire including the following sections:

1. Sociodemographic characteristics: Age, sex, qualification degree, working place, and years of experience

2. Assessment of knowledge regarding COVID19 pandemic

3. Assessment of awareness and attitude of $\mathrm{HCW}$ regarding infection control programs at their institutes (13 questions) (Appendix A).

\section{Statistical analysis}

All collected questionnaires were revised for completeness and logical consistency. Precoded data were entered into Microsoft Office Excel program for Windows, 365. Data were transferred to the Statistical Package for the Social Sciences version 21 (SPSS-V 21) for data analysis. Quantitative variables were described as mean, SD and median and IQ while qualitative variables were expressed as number and percentage. Chi-square test was used to compare qualitative variables between groups. Fisher's exact test was used when expected cells are $<5, p \leq 0.05$ significant and $p<$ 0.01 highly significant.

\section{Ethical consideration}

The study protocol was revised and approved by ethical committees of public health department at Kasr Alainy Hospital (Number: 17, date of approval: 12/7/2020). An electronic informed consent was obtained from all participants before recruitment to the study after explaining the goals of the work. Confidentiality was guaranteed on handling the database and questionnaire forms according to revised Helsinki Deceleration of biomedical ethics (World Medical Association, 2011).

\section{Results}

\section{Basic characteristics of study group}

A total of 544 participants were surveyed, 58 of them were excluded for the missing data. A total of 486 physicians working between university, government, teaching, private hospitals, and polyclinics submitted replies to the questions shown in questionnaires division. The characteristics of the group in terms of age, gender, specialties, qualifications, and institution are shown in Table 1. Nearly two-thirds of the physicians were female $69.5 \%$ (338) with mean age $33.9 \pm 7$ years. Of whom, $46.9 \%$ practiced internal medicine specialty, $35.4 \%$ were pediatricians, and only $17.7 \%$ specialized in family medicine. More than 
$70 \%$ of included physicians had postgraduate degrees (39.5\% master and $32.2 \%$ PHD). More than $67 \%$ practiced their specialties at university institutions (Table 1).

Table 1: Distribution of the study group according to their basic characteristics $n=486(100 \%)$

\begin{tabular}{ll}
\hline Variables & Values \\
\hline Age & $33.9 \pm 7$ \\
Mean \pm SD & $33(29: 38)$ \\
Median (IQR) & \\
Years of experience & $33.9 \pm 7$ \\
$\quad$ Mean \pm SD & $33(29: 38)$ \\
$\quad$ Median (IQR) & \\
Sex (\%) & $338(69.50)$ \\
$\quad$ Female & $148(30.50)$ \\
Male & \\
Specialty (\%) & $228(46.90)$ \\
Internal medicine & $172(35.40)$ \\
Pediatric & $86(17.70)$ \\
Family medicine & \\
Qualification (\%) & $136(28.00)$ \\
Bachelor & $192(39.50)$ \\
Master & $158(32.50)$ \\
PhD & \\
Place of work (\%) & $164(33.70)$ \\
Private hospital & $216(44.40)$ \\
Governmental hospital & $98(20.20)$ \\
Polyclinics & $326(67.10)$ \\
University hospital & $154(31.70)$ \\
$\quad$ Teaching hospital &
\end{tabular}

\section{Causes, contributing factors, and surveillance systems}

By analysis of medical staff responses to questions concerned with awareness regarding infection prevention and control policies and procedures. Only $60.5 \%$ received some form of training or orientation concerning infection prevention and control. Regarding their opinion about following adherence of health-care providers to infection control policies in their institutions, they reported that $50 \%$ of all staff did not show adherence and only $27 \%$ followed them. Questions related to an emerging infectious disease task force or dealing with outbreaks, $37 \%$ of the participants had approved its presence while $23.5 \%$ did not know about it. Regarding the participants' view about awareness regarding differentiation between different isolation protocols by all staff, they reported that $42 \%$ cannot discriminate and only $31.7 \%$ can. The response to the question concerning the hospitals preparation for any infections outbreaks was disagreed by $56.6 \%$ of the participants and only $25.2 \%$ approved that. Through assessment of physicians response to awareness of medical staff about surveillance system of the infectious diseases at their institutions, unfortunately, it was found that $64.2 \%$ of the participant did not know which infections are reported to Ministry of Health $(\mathrm{MOH})$ and $46.1 \%$ did not know if there was turnaround time of laboratory results of the recordable infectious agents or not. About $42 \%$ and $39 \%$ of the contributors stated that the reporting systems in their hospitals were telephone communication or paper version, respectively. Concerning the physicians' opinion about effectiveness of the used surveillance tool to control infection, only $21 \%$ were concordance and $52.5 \%$ were not. There was also some variation in participants' response to questions related to the causes of the outbreak as $43.8 \%$ referred that to shortage of proper personal protective equipment (PPE) and only $7.4 \%$ assigned the carelessness of HCWs as a reason of outbreaks. Moreover, $71.4 \%$ reported insufficient resources to fulfill the infection control requirements as a primary factor that contributed to the spread of infection in the hospital (Table 2).

Table 2: Distribution of the study group according to their knowledge regarding infection control, surveillance system, and contributing factors to outbreaks at their institutions $\mathrm{n}=\mathbf{4 8 6}(\mathbf{1 0 0 \% )}$

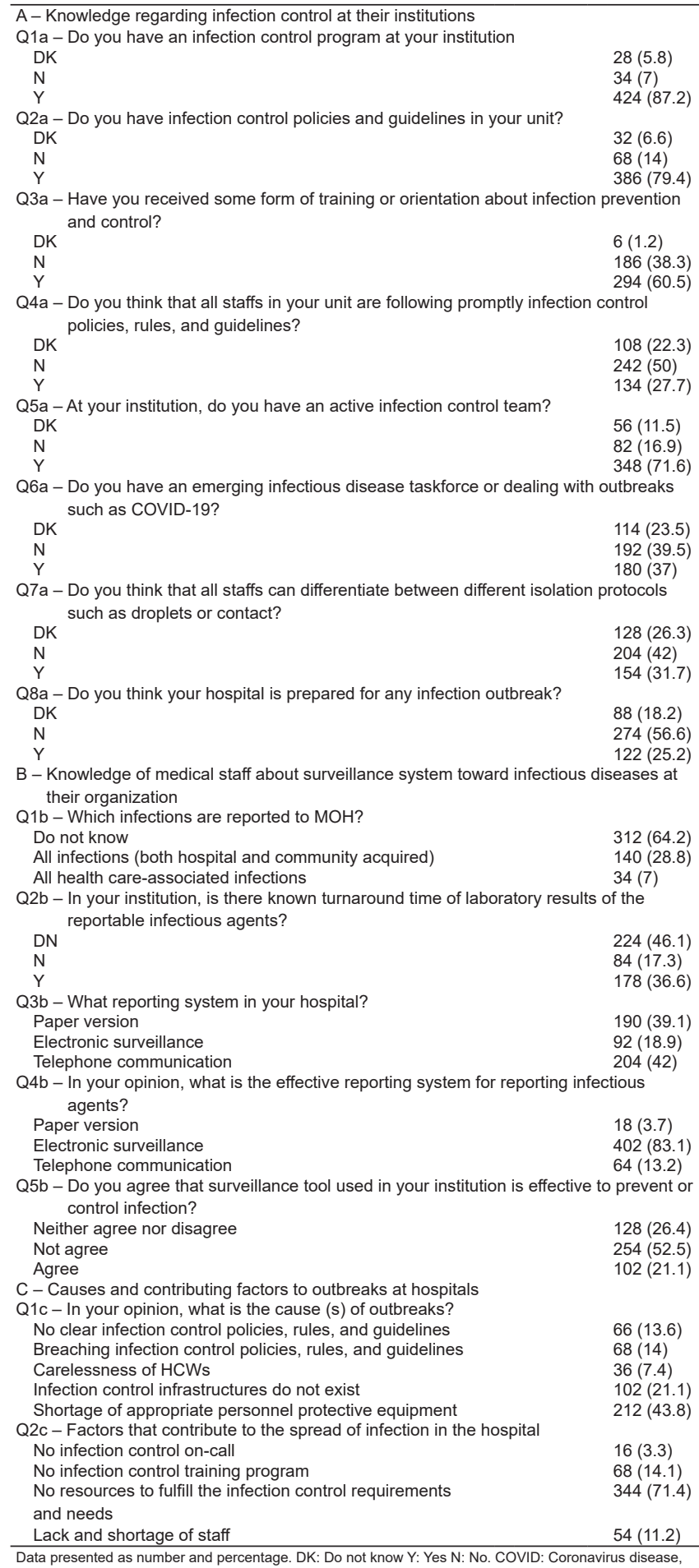
HCWs: Health care workers, MOH: Ministry of Health. 


\section{Awareness and attitude responses according the specialties}

The study revealed that there was a statistically significant difference ( $p \leq 0.05$ ) among medical staff according to their specialties regarding their knowledge of infection control at their institutions, where $93 \%$ of family medicine medical staff reported having infection control program at their institutions. Nearly $87.2 \%$ of pediatric medical staff reported having infection control policies and guidance at their units, whereas $7.9 \%$ of internal medicine medical staff stated that they do not know ( $p<0.001$ ), while $42.1 \%$ and $43.1 \%$ of internal medicine and pediatric medical staff, respectively, stated that they did not receive any training of infection prevention and control. About $44.2 \%$ of family medicine medical staff stated that staff at their units following rules and policies of infection control, while $62.8 \%$ of internal medicine medical staff stated "no" and $26.7 \%$ of pediatric medical staff stated that they "don't know" ( $p<0.001)$. Majority of the participants have infection control teams at their units, $23.4 \%$ of medical staff did not know about the emerging infectious diseases task force. While $42 \%$ of medical staff Stated their non-capability to differentiate between different isolation strategies. The Majority (56.3\%) stated unpreparedness to face the outbreak (Table 3 ).

Table 3: Distribution of the study group by their specialties according to their knowledge regarding infection control, surveillance system, and contributing factors to outbreaks at their institutions $n=486(100 \%)$

\begin{tabular}{|c|c|c|c|c|}
\hline Questions & Internal medicine $\mathrm{n}(\%)$ & Pediatric $\mathrm{n}(\%)$ & Family medicine $\mathrm{n}(\%)$ & $\mathrm{p}$-value \\
\hline \multirow{2}{*}{\multicolumn{5}{|c|}{$\begin{array}{l}\text { A Questions Knowledge regarding infection control } \\
\text { Q1a - Do you have an infection control program at your institution? }\end{array}$}} \\
\hline & & & & \\
\hline DK & $20(8.8)$ & $4(2.3)$ & $4(4.7)$ & \multirow[t]{3}{*}{0.021} \\
\hline $\mathrm{N}$ & $18(7.9)$ & $14(8.1)$ & $2(2.3)$ & \\
\hline Y & $190(83.3)$ & $154(89.5)$ & $80(93)$ & \\
\hline \multicolumn{5}{|l|}{ Q2a - Do you have infection control policies and guidelines in your unit? } \\
\hline DK & $18(7.9)$ & $8(4.7)$ & $6(7)$ & \multirow[t]{3}{*}{$<0.001$} \\
\hline $\mathrm{N}$ & $48(21.1)$ & $14(8.1)$ & $6(7)$ & \\
\hline $\mathrm{Y}$ & $162(71.1)$ & $150(87.2)$ & $74(86)$ & \\
\hline \multicolumn{5}{|c|}{ Q3a - Have you received some form of training or orientation about infection prevention and control? } \\
\hline DK & $2(0.9)$ & $4(2.3)$ & $0(0)$ & \multirow{3}{*}{$<0.001$} \\
\hline $\mathrm{N}$ & $96(42.1)$ & $74(43)$ & $16(18.6)$ & \\
\hline $\mathrm{Y}$ & $130(57)$ & $94(54.7)$ & $70(81.4)$ & \\
\hline \multicolumn{5}{|c|}{ Q4a - Do you think that all staffs in your unit are following promptly infection control policies, rules, and guidelines? } \\
\hline DK & $42(18.6)$ & $46(26.7)$ & $20(23.3)$ & \multirow[t]{3}{*}{$<0.001$} \\
\hline $\mathrm{N}$ & $142(62.8)$ & $72(41.9)$ & $28(32.6)$ & \\
\hline $\mathrm{Y}$ & $42(18.6)$ & $54(31.4)$ & $38(44.2)$ & \\
\hline \multicolumn{5}{|l|}{ Q5a - At your institution, do you have an active infection control team? } \\
\hline DK & $30(13.2)$ & $18(10.5)$ & $8(9.3)$ & 0.033 \\
\hline $\mathrm{N}$ & $34(14.9)$ & $40(23.3)$ & $8(9.3)$ & \\
\hline $\mathrm{Y}$ & $164(71.9)$ & $114(66.3)$ & $70(81.4)$ & \\
\hline Q6a-Do you have an emerging infectious disease taskforce or de & tbreaks such as COVID- & & & \\
\hline DK & $56(24.6)$ & $44(25.6)$ & $14(16.3)$ & $<0.001$ \\
\hline $\mathrm{N}$ & $110(48.2)$ & 70 (40.7) & $12(14)$ & \\
\hline $\mathrm{Y}$ & $62(27.2)$ & $58(33.7)$ & $60(69.8)$ & \\
\hline Q7a - Do you think that all staffs can differentiate between differen & otocols such as droplets & & & \\
\hline DK & $68(29.8)$ & $36(20.9)$ & $24(27.9)$ & 0.071 \\
\hline $\mathrm{N}$ & $98(43)$ & 68 (39.5) & $38(44.2)$ & \\
\hline $\mathrm{Y}$ & $62(27.2)$ & 68 (39.5) & $24(27.9)$ & \\
\hline Q8a - Do you think your hospital is prepared for any infection outb & & & & \\
\hline DK & $48(21.2)$ & $32(18.6)$ & $8(9.3)$ & 0.006 \\
\hline $\mathrm{N}$ & $126(55.8)$ & $104(60.5)$ & $44(51.2)$ & \\
\hline $\mathrm{Y}$ & $52(23)$ & $36(20.9)$ & 34 (39.5) & \\
\hline B - Knowledge regarding surveillance system toward infectious di & & & & \\
\hline Q1b - Is your hospital is enrolled in national surveillance system? & & & & \\
\hline DK & $104(45.6)$ & $64(37.2)$ & $30(34.9)$ & 0.03 \\
\hline $\mathrm{N}$ & $58(25.4)$ & $50(29.1)$ & $16(18.6)$ & \\
\hline $\mathrm{Y}$ & $66(28.9)$ & $58(33.7)$ & $40(46.5)$ & \\
\hline Q2b - Do you have a list of reportable infectious agents available & tal? & & & \\
\hline DK & $64(28.1)$ & $56(32.6)$ & $28(32.6)$ & 0.005 \\
\hline $\mathrm{N}$ & $108(47.4)$ & $64(37.2)$ & $22(25.6)$ & \\
\hline $\mathrm{Y}$ & $56(24.6)$ & $52(30.2)$ & $36(41.9)$ & \\
\hline Q3b - Which infections are reported to $\mathrm{MOH}$ ? & & & & \\
\hline DK & $154(67.5)$ & $106(61.6)$ & $52(60.5)$ & 0.011 \\
\hline All infections (both hospital and community acquired) & $58(25.4)$ & $60(34.9)$ & $22(25.6)$ & \\
\hline All health care-associated infections & $16(7)$ & $6(3.5)$ & $12(14)$ & \\
\hline Q4b - In your institution, is there known turnaround time of laborat & f the reportable infectious & & & \\
\hline DK & $126(55.3)$ & $62(36)$ & $36(41.9)$ & $<0.001$ \\
\hline $\mathrm{N}$ & $42(18.4)$ & $26(15.1)$ & $16(18.6)$ & \\
\hline $\mathrm{Y}$ & $60(26.3)$ & $84(48.8)$ & 34 (39.5) & \\
\hline Q5b - What reporting system in your hospital? & & & & \\
\hline Paper version & $80(35.1)$ & $76(44.2)$ & $34(39.5)$ & 0.1 \\
\hline Electronic surveillance & $54(23.7)$ & $26(15.1)$ & $12(14)$ & \\
\hline Telephone communication & $94(41.2)$ & 70 (40.7) & $40(46.5)$ & \\
\hline Q6b - In your opinion, what is the effective reporting system for re & ious agents? & & & \\
\hline Paper version & $8(3.5)$ & $8(4.7)$ & $2(2.3)$ & $<0.001$ \\
\hline Electronic surveillance & $192(85)$ & $126(73.3)$ & $84(97.7)$ & \\
\hline Telephone communication & $26(11.5)$ & $38(22.1)$ & $0(0)$ & \\
\hline Q7b - Do you agree that surveillance tool used in your institution & prevent or control infectic & & & \\
\hline Neither agree nor disagree & $80(35.4)$ & $32(18.6)$ & $16(18.6)$ & $<0.001$ \\
\hline Not agree & $112(49.6)$ & $94(54.7)$ & $48(55.8)$ & \\
\hline Agree & $34(15)$ & $46(26.7)$ & $22(25.6)$ & \\
\hline C-Causes and contributing factors to outbreaks at hospitals & & & & \\
\hline Q1c - In your opinion what is the causes of outbreaks? & & & & \\
\hline No clear infection control policies, rules, and guidelines & $34(15)$ & $26(15.1)$ & $6(7)$ & 0.063 \\
\hline Breaching infection control policies, rules, and guidelines & 34 (15) & 24 (14) & $10(11.6)$ & \\
\hline Carelessness of HCWs & $18(8)$ & $12(7)$ & $6(7)$ & \\
\hline Infection control infrastructures do not exist & $56(24.8)$ & $24(14)$ & $22(25.6)$ & \\
\hline Shortage of appropriate personnel protective equipment & $84(37.2)$ & $86(50)$ & $42(48.8)$ & \\
\hline Q2C - Factors that contribute to the spread of infection in the hosp & & & & \\
\hline No infection control on-call & $4(1.8)$ & $12(7)$ & $0(0)$ & $<0.001$ \\
\hline No infection control training program & $40(17.9)$ & $24(14)$ & $4(4.7)$ & \\
\hline No resources to fulfill the infection control requirements and needs & $162(72.3)$ & $108(62.8)$ & $74(86)$ & \\
\hline Lack and shortage of staff & $18(8)$ & $28(16.3)$ & $8(9.3)$ & \\
\hline
\end{tabular}


Regarding awareness of HCWs concerning surveillance systems toward infectious diseases at their institutions (Table 3 ), the study revealed that $46.5 \%$ of family medicine staff stated that their hospital is enrolled in the national surveillance system, while $29.1 \%$ and $45.6 \%$ of pediatric and internal medicine staff stated "No \& Don't know," respectively. In addition, $97.7 \%$ of family medicine staff stated electronic surveillance, while $22.1 \%$ of pediatric staff stated telephone surveillance. Most of the respondents denied the effectiveness of surveillance tools in their institutes. On the other side, there was no statistical difference of significance regarding the response of staff by specialties to their opinion concerning the causes of outbreaks at their hospitals.

The study revealed that the absence of resources to fulfill the infection control requirements and needs is a main contributing factor to spread of infection in hospital $(p<0.001)$, otherwise, there was no statistical difference regarding the response of staff by their specialties to their opinion concerning the causes of outbreaks at their hospitals $(p=0.063)$.

\section{Awareness and knowledge responses according to the qualification's certifications}

The study revealed that there was a statistically significant difference with $p \leq 0.05$ among medical staff according to qualifications regarding their knowledge of infection control at their institutions (Table 4). The trend of orientation for infection control is toward the highly certificated individuals (having $\mathrm{PhD}$ ). On the other hand, there was no statistically significant difference with $p=0.172$ and $p=0.212$ in response of staff to questions related to receiving training concerning infection control and prompt following infection control policies, respectively. The study revealed that there was variation in response among medical staff according to their qualifications regarding their knowledge of surveillance systems toward infectious diseases at their institutions (Table 4). There was a statistical difference of significant with $p<0.001$ among staff in response to which infections are reported to $\mathrm{MOH}$. Furthermore, there was a statistical difference of significant with $p=0.002$ and 0.001 in response of staff if there was known turnaround time of laboratory results of reported infectious agents? and What reporting system in their hospital? respectively. The study also revealed statistical differences of significance with $p=0.008$ and $<0.001$ in response of staff to what is the effective reporting system for reporting infectious agents? and If they agree that surveillance tools used in your institution are effective to prevent and control infections, respectively. On the other hand, there was no statistical difference of significant with $p=0.149$ and 0.054 in response of staff if their hospital is enrolled in the national surveillance system and if they have a list of reportable infectious agents available in their hospital, respectively. The study revealed statistical differences of significance among staff by their qualification according to their response to causes of outbreaks at their hospitals with $p=0.048$. Furthermore, there was a statistical difference of significance among staff in response to factors contributing to spread of infections at their hospitals with $p<0.001$ (Table 4).

\section{Awareness and knowledge responses according to the years of experience}

The study revealed a significant statistical difference among staff by years of experience concerning their knowledge regarding infection control at their institutions (Table 5). In response whether they have an infection control program and guidelines, the study also revealed a statistical difference of significance with $p<0.032$ in response of staff if they think all staffs in their unit are following promptly infection control policies. The response of staff if they have an active infection control team at their institution was a statistical difference of significant with $p<0.001$. The study also revealed a statistical difference of significance with $p=0.002$ in response of staff if they have an emerging infectious disease task force or dealing with outbreaks such as COVID-19. There was a statistical difference of significance with $p<0.001$ in response of staff if they think that their hospital is prepared for any infection outbreak. On the other hand, there was no statistical difference of significance with $p=0.292$ and $p=0.094$ in response of staff if they received some form of training or orientation about infection prevention and control and if they think that all staffs can differentiate between isolation protocol as droplet or contact, respectively.

The study revealed statistical difference of significance among the groups of higher and lower years of experience in response to questions regarding surveillance system toward infectious diseases at their institutions concerning awareness of the presence of surveillance tool used in their institutions, if it is effective to prevent or control infection, reporting path tool $\mathrm{p}<0.05$ (Table 5).

\section{Responses according to the types of hospital sectors}

There was variation in responses among participants to questions according to the type of their institutions (Table 6). Response to question if there is an infection control program at their institution or not, the study revealed that there was statistical difference of significance regarding awareness of the presence of active infection control policy at the governmental and university hospitals with $p<0.05$. There was also significant variation in responses to the question if the institution had an emerging infectious diseases task force with $(P=0.003)$. Majority of the health workers in governmental $(76.5 \%)$, university $(58.7 \%)$, and teaching 
Table 4: Distribution of the study group by qualification according to their knowledge regarding infection control, surveillance system, and contributing factors to outbreaks at their institutions $n=486(100 \%)$

\begin{tabular}{|c|c|c|c|c|}
\hline \multirow[t]{2}{*}{ Questions } & \multicolumn{3}{|l|}{ Qualification } & \multirow[t]{2}{*}{ p-value } \\
\hline & Bachelor, n (\%) & Master, n (\%) & $\mathrm{PhD}, \mathrm{n}(\%)$ & \\
\hline \multicolumn{5}{|l|}{ A-Knowledge regarding infection control } \\
\hline \multicolumn{5}{|l|}{ Q1a - Do you have an infection control program at your institution? } \\
\hline DK & $14(10.3)$ & $10(5.2)$ & $4(2.5)$ & \multirow[t]{3}{*}{$<0.001$} \\
\hline $\mathrm{N}$ & $16(11.8)$ & $16(8.3)$ & $2(1.3)$ & \\
\hline $\mathrm{Y}$ & $106(77.9)$ & $166(86.5)$ & $152(96.2)$ & \\
\hline \multicolumn{5}{|l|}{ Q2a - Do you have infection control policies and guidelines in your unit? } \\
\hline DK & $16(11.8)$ & $14(7.3)$ & $2(1.3)$ & \multirow[t]{3}{*}{$<0.001$} \\
\hline $\mathrm{N}$ & $32(23.5)$ & $28(14.6)$ & $8(5.1)$ & \\
\hline $\mathrm{Y}$ & $88(64.7)$ & $150(78.1)$ & $148(93.7)$ & \\
\hline \multicolumn{5}{|c|}{ Q3a - Have you received some form of training or orientation about infection prevention and control? } \\
\hline DK & $2(1.5)$ & $4(2.1)$ & $0(0)$ & 0.172 \\
\hline $\mathrm{N}$ & $60(44.1)$ & $66(34.4)$ & $60(38)$ & \\
\hline $\mathrm{Y}$ & $74(54.4)$ & $122(63.5)$ & $98(62)$ & \\
\hline Q4a - Do you think that all staffs in your unit are following promptly & policies, rules, an & & & \\
\hline DK & $26(19.1)$ & $52(27.1)$ & $30(19.2)$ & 0.212 \\
\hline $\mathrm{N}$ & 76 (55.9) & $86(44.8)$ & $80(51.3)$ & \\
\hline $\mathrm{Y}$ & $34(25)$ & $54(28.1)$ & 46 (29.5) & \\
\hline Q5a - At your institution, do you have an active infection control tea & & & & \\
\hline DK & $34(25)$ & $18(9.4)$ & $4(2.5)$ & $<0.001$ \\
\hline $\mathrm{N}$ & $14(10.3)$ & $60(31.3)$ & $8(5.1)$ & \\
\hline $\mathrm{Y}$ & $88(64.7)$ & $114(59.4)$ & $146(92.4)$ & \\
\hline Q6a-Do you have an emerging infectious disease taskforce or dea & aks such as COVI & & & \\
\hline DK & $30(22.1)$ & $46(24)$ & $38(24.1)$ & $<0.001$ \\
\hline $\mathrm{N}$ & $74(54.4)$ & $84(43.8)$ & $34(21.5)$ & \\
\hline $\mathrm{Y}$ & $32(23.5)$ & $62(32.3)$ & $86(54.4)$ & \\
\hline Q7a - Do you think that all staff can differentiate between different is & s such as droplets & & & \\
\hline $\mathrm{DK}$ & $40(29.4)$ & $38(19.8)$ & $50(31.6)$ & 0.001 \\
\hline $\mathrm{N}$ & $48(35.3)$ & $80(41.7)$ & $76(48.1)$ & \\
\hline Y & $48(35.3)$ & 74 (38.5) & $32(20.3)$ & \\
\hline Q8a - Do you think your hospital is prepared for any infection outbre & & & & \\
\hline DK & $14(10.3)$ & $36(18.8)$ & $38(24.4)$ & $<0.001$ \\
\hline $\mathrm{N}$ & 98 (72.1) & $114(59.4)$ & $62(39.7)$ & \\
\hline $\mathrm{Y}$ & $24(17.6)$ & $42(21.9)$ & 56 (35.9) & \\
\hline B - Knowledge regarding surveillance system toward infectious dise & & & & \\
\hline Q1b - Is your hospital is enrolled in national surveillance system? & & & & \\
\hline DK & $64(47.1)$ & $68(35.4)$ & $66(41.8)$ & 0.149 \\
\hline $\mathrm{N}$ & $32(23.5)$ & $58(30.2)$ & $34(21.5)$ & \\
\hline $\mathrm{Y}$ & $40(29.4)$ & $66(34.4)$ & $58(36.7)$ & \\
\hline Q2b - Do you have a list of reportable infectious agents available in & & & & \\
\hline DK & $48(35.3)$ & $44(22.9)$ & $56(35.4)$ & 0.054 \\
\hline $\mathrm{N}$ & 54 (39.7) & $82(42.7)$ & $58(36.7)$ & \\
\hline $\mathrm{Y}$ & $34(25)$ & $66(34.4)$ & $44(27.8)$ & \\
\hline $\mathrm{Q} 3 \mathrm{~b}$ - Which infections are reported to $\mathrm{MOH}$ ? & & & & \\
\hline DK & $104((76.5)$ & $112(58.3)$ & $96(60.8)$ & $<0.001$ \\
\hline All infections (both hospital and community acquired) & $32(23.5)$ & $66(34.4)$ & $42(26.6)$ & \\
\hline All health care-associated infections & $0(0)$ & $14(7.3)$ & $20(12.7)$ & \\
\hline Q4b - In your institution, is there known turnaround time of laborato & reportable infectio & & & \\
\hline DK & $74(54.4)$ & $74(38.5)$ & $76(48.1)$ & 0.002 \\
\hline $\mathrm{N}$ & $24(17.6)$ & $44(22.9)$ & $16(10.1)$ & \\
\hline $\mathrm{Y}$ & $38(27.9)$ & $74(38.5)$ & $66(41.8)$ & \\
\hline Q5b - What reporting system in your hospital? & & & & \\
\hline Paper version & $60(44.1)$ & $58(30.2)$ & $72(45.6)$ & 0.001 \\
\hline Electronic surveillance & $16(11.8)$ & $40(20.8)$ & $36(22.8)$ & \\
\hline Telephone communication & $60(44.1)$ & $94(49)$ & $50(31.6)$ & \\
\hline Q6b - In your opinion, what is the effective reporting system for repc & agents? & & & \\
\hline Paper version & $4(2.9)$ & $12(6.3)$ & $2(1.3)$ & 0.008 \\
\hline Electronic surveillance & $108(79.4)$ & $152(79.2)$ & $142(91)$ & \\
\hline Telephone communication & $24(17.6)$ & $28(14.6)$ & $12(7.7)$ & \\
\hline Q7b - Do you agree that surveillance tool used in your institution is & ent or control infe & & & \\
\hline Neither agree nor disagree & $36(26.5)$ & $42(21.9)$ & $50(32.1)$ & $<0.001$ \\
\hline Not agree & $86(63.2)$ & $94(49)$ & $74(47.4)$ & \\
\hline Agree & $14(10.3)$ & $56(29.2)$ & $32(20.5)$ & \\
\hline C-Causes and contributing factors to outbreaks at hospitals & & & & \\
\hline Q1c - In your opinion, what are the causes of outbreaks? & & & & \\
\hline No clear infection control policies, rules, and guidelines & $16(11.8)$ & $36(18.8)$ & $14(9)$ & 0.048 \\
\hline Breaching infection control policies, rules, and guidelines & $20(14.7)$ & $20(10.4)$ & 28 (17.9) & \\
\hline Carelessness of HCWs & $6(4.4)$ & $20(10.4)$ & $10(6.4)$ & \\
\hline Infection control infrastructures do not exist & $30(22.1)$ & $36(18.8)$ & $36(23.1)$ & \\
\hline Shortage of appropriate personnel protective equipment & $64(47.1)$ & $80(41.7)$ & $68(43.6)$ & \\
\hline Q2c - Factors that contribute to the spread of infection in the hospit & & & & \\
\hline No infection control on-call & $4(3)$ & $12(6.3)$ & $0(0)$ & 0.001 \\
\hline No infection control training program & $24(17.9)$ & $24(12.5)$ & $20(12.8)$ & \\
\hline No resources to fulfill the infection control requirements and needs & $100(74.6)$ & $126(65.6)$ & $118(75.6)$ & \\
\hline Lack and shortage of staff & $6(4.5)$ & $30(15.6)$ & $18(11.5)$ & \\
\hline
\end{tabular}

hospitals $(85.7 \%)$ stated that their institutions were not well ready to face outbreaks $(p=0.001)$. Majority of the participants did not know which type of infection reported to $\mathrm{MOH}(\mathrm{p}=0.007)$.

Regarding the response to question if the staff can differentiate between different isolation protocols such as droplets or contact, the response was significantly more likely to respond "No or don't know" ( $p=0.012$ ). Paper version of surveillance is the reporting system in governmental and university hospitals ( $p=0.034$ ), however, as expected the most recommended effective reporting system to be is electronic version. More than half of the participants did not agree that surveillance tools used in their institution 
Table 5: Distribution of the study group by years of experience according to their knowledge regarding infection control, surveillance system, and contributing factors to outbreaks at their institutions $n=486(100 \%)$

\begin{tabular}{|c|c|c|c|}
\hline \multirow[t]{2}{*}{ Questions } & \multicolumn{2}{|c|}{ Years of experience } & \multirow[t]{2}{*}{ p-value } \\
\hline & $\leq 8 \mathrm{n}(\%)$ & More than $8 \mathrm{n}(\%)$ & \\
\hline \multicolumn{4}{|l|}{ Do you have an infection control program at your institution } \\
\hline Do not know & $22(9)$ & $6(2.5)$ & \multirow[t]{3}{*}{$<0.001$} \\
\hline No & $24(9.8)$ & $10(4.1)$ & \\
\hline Yes & $198(81.1)$ & $226(93.4)$ & \\
\hline \multicolumn{4}{|l|}{ Do you have infection control policies and guidelines in your unit? } \\
\hline Do not know & $26(10.7)$ & $6(2.5)$ & \multirow[t]{3}{*}{$<0.001$} \\
\hline No & $46(18.9)$ & $22(9.1)$ & \\
\hline Yes & $172(70.5)$ & $214(88.4)$ & \\
\hline \multicolumn{4}{|c|}{ Have you received some form of training or orientation about infection prevention and control? } \\
\hline Do not know & $6(2.5)$ & $0(0)$ & \multirow[t]{3}{*}{0.027} \\
\hline No & $98(40.2)$ & $88(36.4)$ & \\
\hline Yes & $140(57.4)$ & $154(63.6)$ & \\
\hline \multicolumn{4}{|c|}{ Do you think that all staff in your unit are following promptly infection control policies, rules, and guidelines } \\
\hline Do not know & $62(25.4)$ & $46(19.2)$ & \multirow[t]{3}{*}{0.002} \\
\hline No & $132(54.1)$ & $110(45.8)$ & \\
\hline Yes & $50(20.5)$ & $84(35)$ & \\
\hline At your institution, do you have an active infection control team? & & & \\
\hline Do not know & $42(17.2)$ & $14(5.8)$ & $<0.001$ \\
\hline No & $46(18.9)$ & $36(14.9)$ & \\
\hline Yes & $156(63.9)$ & $192(79.3)$ & \\
\hline Do you have an emerging infectious disease taskforce or dealing with & & & \\
\hline Do not know & $58(23.8)$ & $56(23.1)$ & $<0.001$ \\
\hline No & $116(47.5)$ & $76(31.4)$ & \\
\hline Yes & $70(28.7)$ & $110(45.5)$ & \\
\hline Do you think that all staff can differentiate between different isolation $p$ & & & \\
\hline Do not know & $66(27)$ & $62(25.6)$ & 0.267 \\
\hline No & $94(38.5)$ & $110(45.5)$ & \\
\hline Yes & $84(34.4)$ & $70(28.9)$ & \\
\hline Do you think your hospital is prepared for any infection outbreak? & & & \\
\hline Do not know & $44(18)$ & $44(18.3)$ & $<0.001$ \\
\hline No & $160(65.6)$ & $114(47.5)$ & \\
\hline Yes & $40(16.4)$ & $82(34.2)$ & \\
\hline Is your hospital is enrolled in national surveillance system & & & \\
\hline Do not know & $104(42.6)$ & $94(38.8)$ & 0.696 \\
\hline No & $60(24.6)$ & $64(26.4)$ & \\
\hline Yes & $80(32.8)$ & $84(34.7)$ & \\
\hline Do you have a list of reportable infectious agents available in your hos & & & \\
\hline Do not know & $72(29.5)$ & $76(31.4)$ & 0.867 \\
\hline No & $100(41)$ & $94(38.8)$ & \\
\hline Yes & $72(29.5)$ & $72(29.8)$ & \\
\hline Which infections are reported to $\mathrm{MOH}$ ? & & & \\
\hline Do not know & $168(68.9)$ & $144(59.5)$ & $<0.001$ \\
\hline All infections (both hospital and community acquired) & $72(29.5)$ & $68(28.1)$ & \\
\hline All health care-associated infections & $4(1.6)$ & $30(12.4)$ & \\
\hline In your institution, is there known turnaround time of laboratory results & & & \\
\hline Do not know & $114(46.7)$ & $110(45.5)$ & 0.796 \\
\hline No & $44(18)$ & $40(16.5)$ & \\
\hline Yes & $86(35.2)$ & $92(38)$ & \\
\hline What reporting system in your hospital & & & \\
\hline Paper version & $82(33.6)$ & $108(44.6)$ & $<0.001$ \\
\hline Electronic surveillance & $36(14.8)$ & $56(23.1)$ & \\
\hline Telephone communication & $126(51.6)$ & $78(32.2)$ & \\
\hline In your opinion, what is the effective reporting system for reporting infe & & & \\
\hline Paper version & $8(3.3)$ & $10(4.2)$ & 0.109 \\
\hline Electronic surveillance & $196(80.3)$ & $206(85.8)$ & \\
\hline Telephone communication & $40(16.4)$ & $24(10)$ & \\
\hline Do you agree that surveillance tool used in your institution is effective & & & \\
\hline Neither agree nor disagree & $54(22.1)$ & $74(30.8)$ & $<0.001$ \\
\hline Not agree & $152(62.3)$ & $102(42.5)$ & \\
\hline Agree & $38(15.6)$ & $64(26.7)$ & \\
\hline In your opinion what are the causes of outbreaks & & & \\
\hline No clear infection control policies, rules, and guidelines & $36(14.8)$ & $30(12.5)$ & 0.873 \\
\hline Breaching infection control policies, rules, and guidelines & $36(14.8)$ & $32(13.3)$ & \\
\hline Carelessness of HCWs & $16(6.6)$ & $20(8.3)$ & \\
\hline Infection control infrastructures do not exist & $50(20.5)$ & $52(21.7)$ & \\
\hline Shortage of appropriate personnel protective equipment & $106(43.4)$ & $106(44.2)$ & \\
\hline Factors that contribute to the spread of infection in the hospital & & & \\
\hline No infection control on-call & $16(6.6)$ & $0(0)$ & $<0.001$ \\
\hline No infection control training program & $36(14.9)$ & $32(13.3)$ & \\
\hline No resources to fulfill the infection control requirements and needs & $174(71.9)$ & $170(70.8)$ & \\
\hline Lack and shortage of staff & $16(6.6)$ & $38(15.8)$ & \\
\hline
\end{tabular}

are effective to prevent or control infection $(p=0.022)$. The study revealed that the most common cause of outbreaks was shortage of right PPE across all three institution types $(p=0.002)$.
The top-cited identifiable factor that contributed to the spread of infection in the hospitals was absence of resources to fulfill the infection control requirements and needs $(p=0.001)$. 
Table 6: Distribution of the study group according to place of work regarding their knowledge concerning infection control, surveillance system, and contributing factors to outbreaks at their institutions

\begin{tabular}{|c|c|c|c|c|}
\hline \multirow[t]{2}{*}{ Questions } & \multicolumn{3}{|l|}{ Place of work } & \multirow[t]{2}{*}{ p-value } \\
\hline & $\begin{array}{l}\text { Governmental hospital, } \mathrm{n}=102 \\
\mathrm{n}(\%)\end{array}$ & $\begin{array}{l}\text { University hospital, } \mathrm{n}=152 \\
\mathrm{n}(\%)\end{array}$ & $\begin{array}{l}\text { Teaching hospital, } \mathrm{n}=14 \\
\mathrm{n}(\%)\end{array}$ & \\
\hline \multicolumn{5}{|l|}{ Do you have an infection control program at your institution } \\
\hline Do not know & $4(3.9)$ & $16(10.5)$ & $0(0)$ & \multirow[t]{3}{*}{0.074} \\
\hline No & $14(13.7)$ & $10(6.6)$ & $2(14.3)$ & \\
\hline Yes & $84(82.4)$ & $126(82.9)$ & $12(85.7)$ & \\
\hline \multicolumn{5}{|l|}{ Do you have infection control policies and guidelines in your unit } \\
\hline Do not know & $4(3.9)$ & $14(9.2)$ & $0(0)$ & \multirow[t]{3}{*}{0.009} \\
\hline No & $8(7.8)$ & $32(21.1)$ & $4(28.6)$ & \\
\hline Yes & $90(88.2)$ & $106(69.7)$ & $10(71.4)$ & \\
\hline \multicolumn{5}{|c|}{ Have you received some form of training or orientation about infection prevention and control? } \\
\hline Do not know & $0(0)$ & $2(1.3)$ & $0(0)$ & \multirow[t]{3}{*}{0.137} \\
\hline No & $36(35.3)$ & $64(42.1)$ & $2(14.3)$ & \\
\hline Yes & $66(64.7)$ & $86(56.6)$ & $12(85.7)$ & \\
\hline \multicolumn{5}{|c|}{ Do you think that all staffs in your unit are following promptly infection control policies, rules, and guidelines } \\
\hline Do not know & $22(21.6)$ & $34(22.7)$ & $2(14.3)$ & 0.965 \\
\hline No & $50(49)$ & $74(49.3)$ & $8(57.1)$ & \\
\hline Yes & $30(29.4)$ & $42(28)$ & $4(28.6)$ & \\
\hline At your institution do you have an active infection control team & & & & \\
\hline Do not know & $8(7.8)$ & $22(14.5)$ & $0(0)$ & $<0.001$ \\
\hline No & $28(27.5)$ & $12(7.9)$ & $6(42.9)$ & \\
\hline Yes & $66(64.7)$ & $118(77.6)$ & $8(57.1)$ & \\
\hline Do you have an emerging infectious disease taskforce or dealing with & tbreaks such as COVID-19? & & & \\
\hline Do not know & $28(27.5)$ & $32(21.1)$ & $4(28.6)$ & 0.003 \\
\hline No & $52(51)$ & $54(35.5)$ & $8(57.1)$ & \\
\hline Yes & $22(21.6)$ & $66(43.4)$ & $2(14.3)$ & \\
\hline Do you think your hospital is prepared for any infection outbreak & & & & \\
\hline Do not know & $4(3.9)$ & $32(21.3)$ & $0(0)$ & 0.001 \\
\hline No & $78(76.5)$ & $88(58.7)$ & $12(85.7)$ & \\
\hline Yes & 20 (19.6) & $30(20)$ & $2(14.3)$ & \\
\hline Is your hospital is enrolled in national surveillance system & & & & \\
\hline Do not know & $36(35.3)$ & $70(46.1)$ & $6(42.9)$ & 0.566 \\
\hline No & $32(31.4)$ & $38(25)$ & $4(28.6)$ & \\
\hline Yes & $34(33.3)$ & $44(28.9)$ & $4(28.6)$ & \\
\hline Do you have a list of reportable infectious agents available in your hos & & & & \\
\hline Do not know & $28(27.5)$ & $52(34.2)$ & $4(28.6)$ & 0.209 \\
\hline No & $42(41.2)$ & $72(47.4)$ & $6(42.9)$ & \\
\hline Yes & $32(31.4)$ & $28(18.4)$ & $4(28.6)$ & \\
\hline Which infections are reported to $\mathrm{MOH}$ ? & & & & \\
\hline Do not know & $66(64.7)$ & $112(73.7)$ & $6(42.9)$ & 0.007 \\
\hline All infections (both hospital and community acquired) & $34(33.3)$ & $30(19.7)$ & $8(57.1)$ & \\
\hline All health care-associated infections & $2(2)$ & $10(6.6)$ & $0(0)$ & \\
\hline In your institution, is there known turnaround time of laboratory results & the reportable infectious agents? & & & \\
\hline Do not know & $44(43.1)$ & $74(48.7)$ & $2(14.3)$ & 0.038 \\
\hline No & $28(27.5)$ & $26(17.1)$ & $6(42.9)$ & \\
\hline Yes & $30(29.4)$ & $52(34.2)$ & $6(42.9)$ & \\
\hline Do you think that all staff can differentiate between different isolation $p$ & ocols such as droplets or contact & & & \\
\hline Do not know & $18(17.6)$ & $56(36.8)$ & $6(42.9)$ & 0.012 \\
\hline No & $56(54.9)$ & $62(40.8)$ & $4(28.6)$ & \\
\hline Yes & $28(27.5)$ & $34(22.4)$ & $4(28.6)$ & \\
\hline What reporting system in your hospital & & & & \\
\hline Paper version & $48(47.1)$ & $58(38.2)$ & $10(71.4)$ & 0.034 \\
\hline Electronic surveillance & $22(21.6)$ & $26(17.1)$ & $0(0)$ & \\
\hline Telephone communication & $32(31.4)$ & $68(44.7)$ & $4(28.6)$ & \\
\hline In your opinion, what is the effective reporting system for reporting infe & ous agents: & & & \\
\hline Paper version & $8(7.8)$ & $2(1.3)$ & $0(0)$ & 0.001 \\
\hline Electronic surveillance & $82(80.4)$ & $134(89.3)$ & $8(57.1)$ & \\
\hline Telephone communication & $12(11.8)$ & $14(9.3)$ & $6(42.9)$ & \\
\hline Do you agree that surveillance tool used in your institution is effective & prevent or control infection & & & \\
\hline Neither agree nor disagree & $16(15.7)$ & $42(28)$ & $4(28.6)$ & 0.022 \\
\hline Not agree & $56(54.9)$ & $80(53.3)$ & $10(71.4)$ & \\
\hline Agree & $30(29.4)$ & $28(18.7)$ & $0(0)$ & \\
\hline In your opinion what are the causes of outbreaks & & & & \\
\hline No clear infection control policies, rules, and guidelines & $24(23.5)$ & $16(10.7)$ & $6(42.9)$ & 0.002 \\
\hline Breaching infection control policies, rules, and guidelines & $2(2)$ & $14(9.3)$ & $0(0)$ & \\
\hline Carelessness of HCWs & $10(9.8)$ & $8(5.3)$ & $2(14.3)$ & \\
\hline Infection control infrastructures do not exist & $16(15.7)$ & $36(24)$ & $2(14.3)$ & \\
\hline Shortage of appropriate personnel protective equipment & $50(49)$ & 76 (50.7) & $4(28.6)$ & \\
\hline Factors that contribute to the spread of infection in the hospital & & & & 0.001 \\
\hline No infection control on-call & $0(0)$ & $2(1.3)$ & $2(14.3)$ & \\
\hline No infection control training program & $12(11.8)$ & $24(16)$ & $4(28.6)$ & \\
\hline No resources to fulfill the infection control requirements and needs & $70(68.6)$ & $116(77.3)$ & $8(57.1)$ & \\
\hline Lack and shortage of staff & $20(19.6)$ & $8(5.3)$ & $0(0)$ & \\
\hline
\end{tabular}

\section{Discussion}

The current study pointed out considerable concern on infection control policies among physicians in different health organizations in Egypt which differ among various specialties, qualification credentials, and experience extent. The study objective was to assess awareness of medical doctors to infection prevention and control in health care institutions in Egypt during a pandemic of COVID-19.

The respondents comprise various health institutions including government $(44 \%)$ and private hospitals and polyclinics. Low resources of basic infection control settings like hand hygiene materials and use of personal protective equipment (PEE), 
over-crowdedness, sanitation measures, and uncertainty of infection prevention policy by health worker staff and more likely the health service receiver are the main causes of dispersion of any infectious disease [12], [13].

Overall, the level of knowledge about infection control and prevention among the health workers in this study was satisfactory. Of $60.5 \%$ had reported awareness about infection control policies and guidelines, this is along with a previous report assessing knowledge, attitude, and perception in both Nigeria and Egypt that revealed that most participants (62\%) had considerable knowledge; nevertheless, Chinese and Iranian reports showed higher scores of knowledge during COVID-19 [14], [15].

Like most of the world countries, we face a great challenge against the new worldwide pandemic of COVID-19, this global outbreak that is caused by the novel severe acute respiratory syndrome coronavirus 2 (SARS-CoV-2), resulting in a wide spectrum of symptoms associated with a high risk of case fatality [14]. In addition, this outbreak has a potential burden on medical, social, psychological settings across the world, threatening mainly healthcare workers especially front-line individuals [15]. The matter necessitates an efficient, effective well-organized collaborative strategy to face that dreadful disease.

Responses in the present study suggested relatively high levels of certainty among physicians regarding infection control at a personal and institutional level while there is less grasp of the surveillance and reporting system standards. Most of the respondents recommended electronic surveillance, yet most actual reporting of infectious diseases all over health institutes occurs through the telephone communication followed by paper tools. Half of the participants did not agree that the available reporting system in their institutions is efficient in the prevention of the disease. This is contradicting what concluded by a similar Arabian study that observed a relatively unpredictable uncertainty about infection prevention programs' knowledge and surveillance standards in response to the MERS outbreaks [11]. This disparity in findings may be attributed to the different experiences of physicians and the study population that included various nationalities, other health workers rather than physicians.

At the national and health facility level, many factors affect the spread of any infectious disease including organism-related factors as pathogenicity and virulence, personal immune state, or health facilities related factors as global supply shortages of PPE like wearing a surgical mask, and a gown, gloves, face shield, goggles, and/or visors or lack of clear infection control strategies. Furthermore, it may be due to breaking the infection control rules or exhausted infrastructure [16].

In the current study, the most cited cause of outbreaks was mainly due to shortage of appropriate
PPE and mostly the lack of resources to fulfill infection control needs is attributing factor of infection spread in the hospitals' settings and these are inconsistent with what reported previously during MERSA in Saudi Arabia where poor infrastructure facilities and understaffed hospitals with inattentiveness of health workers [11]

There was evidence of variability between different medical professions, institution types. Increasing the COVID-19 cases among the HCWs across either developed or developing countries reflecting the gaps of infection control policies in health institutes where strict actions are imperative. In the context of the COVID-19 outbreak [17], [18], the WHO recommends measures related to HCWs through ensuring adequate supplies of PPE, adherence to infection control and prevention policies, and procedures for all aspects of health care, establishing a surveillance process for acute respiratory infections potentially caused by COVID-19 virus [19], [20].

In the term of years of experience, there was a significant variation in response to questions related to the knowledge of whether there is an infection control policy in their institution also a significant difference in response to the questions concerning receiving, availability, and accessibility of infection control program in different heath institutions with high uncertainty in those with fewer years of experience this was mainly expected as "don't know" answers among the physician with below 8 years of experience, this is along with a previous survey done in Saudi Arabia which is considered like our society sharing for somehow the same sociodemographic characteristics [11]

Being a fact, $\mathrm{HCW}$ in private hospitals are more satisfied with infection control policy as well as more aware about infection control and prevention guidelines with superior resources than those in governmental health sectors [21], [22], yet in the study, we compare the governmental, teaching, and university hospitals only and discard the private and polyclinic sector due to the overlap of places wok as well as these places of work were the only working hospitals during the curfew. On questions relating to readiness and competence of the institution, it was found that most of the physicians across governmental, university, and teaching hospitals declared unpreparedness of their institutions for the COVID outbreak. And mostly, they did not know which type of infection was reported to $\mathrm{MOH}$. With respect to contributing factors of infection spread and surveillance systems, the participants were more likely to deny the effectiveness of the reporting system in their institutions and also stated that the absence of resources to fulfill the infection control requirements and needs was the most cited cause of infection spread. Moreover, a significant difference across institution types on whether staff can differentiate between different isolation protocols such as droplet or contact. Hence, effective programs for staff training seem to be urgently obliged. Moreover, this is along with Rabaan et al. study [11]. 
It is worth noting some limitations of our study. First, this survey did not provide the identification of the participating institutions specifically. Second the inability of the study to evaluate the grading of awareness and the level of carelessness. Third regarding the institutions types data analysis we could not evaluate private sectors in such comparison due to the overlap of the places of work of medical staff.

\section{Conclusion}

Surveillance and infection control measures are critical to a global public health response. This self-reported questionnaire of HCWs in Egypt had shown reasonable knowledge about infection control and surveillance during the COVID-19 outbreak, yet promotes self-reported infection control behaviors, which may result from the higher workload and lack of resources. The preparedness system including the human resources and PPE storage in the hospitals should be improved to combat the emergent infection flow.

\section{Acknowledgment}

We would like to thank all participants who welcomed to join in this study.

\section{References}

1. World Health Organization. Naming the Coronavirus Disease (COVID-19) and the Virus that Causes It. Geneva: World Health Organization; 2020 :

2. Huang $\mathrm{C}$, Wang $\mathrm{Y}, \mathrm{Li} X$, Ren L, Zhao J, Hu Y, et al. Clinical features of patients infected with 2019 novel Coronavirus in Wuhan, China. Lancet. 2020;395(10223):497-506. https://doi. org/10.1016/s0140-6736(20)30183-5

PMid:31986264

3. Abdulwahab AA. Framing health policy in the context of Saudi Arabia. J Infect Public Health. 2016;9(1):3-6.

PMid:26643214

4. Butt TS, Koutlakis-Barron I, AlJumaah S, AlThawadi S, AlMofada S. Infection control and prevention practices implemented to reduce transmission risk of Middle East respiratory syndrome-Coronavirus in a tertiary care institution in Saudi Arabia. Am J Infect Control. 2016;44(5):605-11. https:// doi.org/10.1016/j.ajic.2016.01.004

PMid:26922892

5. Worldometers, Coronavirus Update (Live); 2020. Available from: https://www.worldometers.info/coronavirus/?utm_campaign $=$ homeadvegas 1 ? $\% 22 \% 20 \% 5 \mathrm{Cl} \% 20 \% 22$ countries. accessed on 2020 Jun 25].

6. Acter T, Uddin N, Das J, Akhter A, Choudhury TR, Kim S. Evolution of severe acute respiratory syndrome Coronavirus 2 (SARSCoV-2) as Coronavirus disease 2019 (COVID-19) pandemic: A global health emergency. Sci Total Environ. 2020;730:138996. https://doi.org/10.1016/j.scitotenv.2020.138996

PMid:32371230

7. de Bruin YB, Lequarre AS, McCourt J, Clevestig $P$, Pigazzani $F$, Jeddi $M Z$, et al. Initial impacts of global risk mitigation measures taken during the combatting of the COVID-19 pandemic. Saf Sci. 2020;128:104773. https://doi. org/10.1016/j.ssci.2020.104773

PMid:32296266

8. Hastings DL, Tokars JI, Aziz IZ, Alkhaldi KZ, Bensadek AT, Alraddadi BM, et al. Outbreak of middle east respiratory syndrome at Tertiary Care Hospital, Jeddah, Saudi Arabia, 2014. Emerg Infect Dis. 2016;22(5):794-801. https://doi.org/10.3201/ eid2205.151797

PMid:27089550

9. Al-Tawfiq JA, Zumla A, Memish ZA. Coronaviruses: Severe acute respiratory syndrome Coronavirus and Middle East respiratory syndrome Coronavirus in travelers. Curr Opin Infect Dis. 2014;27(5):411-7. https://doi.org/10.1097/ qco.0000000000000089 PMid:25033169

10. Hager E, Odetokun IA, Bolarinwa O, Zainab A, Okechukwu O, Ahmad IA. Knowledge, attitude, and perceptions towards the 2019 Coronavirus pandemic: A bi-national survey in Africa. PLoS One. 2020;15(7):e0236918. https://doi.org/10.1371/ journal.pone.0236918 PMid:32726340

11. Rabaan AA, Alhani HM, Bazzi AM, Al-Ahmed SH. Questionnairebased analysis of infection prevention and control in healthcare facilities in Saudi Arabia in regards to Middle East respiratory syndrome. J Infect Public Health. 2017;10(5):548-63. https://doi. org/10.1016/j.jiph.2016.11.008

PMid:28215912

12. Centers for Disease Control and Prevention (CDC). Update: Severe respiratory illness associated with Middle East respiratory syndrome Coronavirus (MERS-CoV)-worldwide, 2012-2013. MMWR Morb Mortal Wkly Rep. 2013;62(23):480-3. https://doi.org/10.1111/ajt.12456 PMid:23760190

13. Centers for Disease Control and Prevention (CDC). Interim Infection Prevention and Control Recommendations for Hospitalized Patients with Middle East Respiratory Syndrome Coronavirus (MERS-CoV); 2015. Available from: https://www. cdc.gov/coronavirus/mers/infection-prevention-control.html. https://doi.org/10.1093/ofid/ofv133.1057

14. Zhong B, Luo W, Li H, Zhang Q, Liu X, Li W, et al. Knowledge, attitudes, and practices towards COVID19 among Chinese residents during the rapid rise period of the COVID-19 outbreak: A quick online cross-sectional survey. Int J Biol Sci. 2020;16(10):1745-52. https://doi.org/10.7150/ijbs.45221 PMid:32226294

15. Erfani A, Shahriarirad R, Ranjbar K, Mirahmadizadeh A, Moghadami M. Knowledge, Attitude and Practice Toward the Novel Coronavirus (COVID-19) Outbreak: A Population-Based Survey in Iran, Bulletin of the World Health Organization; 2020. https://doi.org/10.2471/blt.20.256651

16. Kampf G, Todt D, Pfaender S, Steinmann E. Persistence of Coronaviruses on inanimate surfaces and their inactivation with biocidal agents. J Hosp Infect. 2020;104(3):246-51. https://doi. org/10.1016/j.jhin.2020.01.022

17. Islam MS, Rahman KM, Sun Y, Qureshi M, Abdi I, Chughtai A, Seale H. Current knowledge of COVID-19 and infection 
prevention and control strategies in healthcare settings: A global analysis. Infect Control Hosp Epidemiol. 2020;41(10):1196-206. https://doi.org/10.1017/ice.2020.237

PMid:32408911

18. Macapagal J, Manlapaz CP. Infection control as a subject in the secondary level of education: A theoretical outcomes-based course outline. J Pedagogical Sociol Psychol. 2020;2(2):52-8. https://doi.org/10.33902/jpsp.2020262526

19. World Health Organization. Infection Prevention and Control during Health Care When Novel Coronavirus (nCoV) Infection is Suspected. Geneva: World Health Organization; 2020. Available from: https://www.who.int/publications-detail/infection-preventionand-controlduring-health-care-when-novel-coronavirus-(ncov)infection-is-suspected20200125. [Last accessed on 2020 Feb 10]. https://doi.org/10.1071/hc15950
20. Infection Prevention and Control for the Care of Patients with 2019-nCoV in Healthcare Settings. European Centre for Disease Prevention and Control Website; 2020. Available from: https://www.ecdc.europa.eu/sites/default/files/documents/ nove-coronavirus-infection-prevention-control-patientshealthcaresettings.pdf. [Last accessed on 2020 Feb 10].

21. Al-Hameed F, Wahla AS, Siddiqui S, Ghabashi A, Al-Shomrani M, Al-Thaqafi A, et al. Characteristics and outcomes of Middle East respiratory syndrome Coronavirus patients admitted to an intensive care unit in Jeddah, Saudi Arabia. J Intensive Care Med. 2015;31(5):344-8. https://doi.org/10.1177/0885066615579858 PMid:25862629

22. Brown C. Call for infection control to stem MERS. CMAJ. 2014;186(10):E349.

PMid:24847147

\section{Appendix A}

- We thank you for giving us part of your valuable time to contribute to this scientific research and help in identifying infection control in hospitals during the Covid 19 pandemic.

Please do not write your name. The data of this form is confidential and will not be used for purposes other than scientific research

Age in years

1) Sex
1. Male
2. Female

2) Qualification

1. Bachelor

2. Master

3. Md degree

3) Working place (more than one answer accepted)

1. Private hospital

2. Governmental hospital

3. Polyclinics

4. University hospital

5. Teaching hospital

4) Years of experience .............

5) Source of COVID-19 information

1. Television

2. Social media

3. Websites of hospital/Health Ministry

6) Do you have an infection control program at your institution?
1. Yes
2. No 3. Don't know

7) Do you have infection control policies and guidelines in your unit?
1. Yes
2. No 3. Don't know

8) Have you received some form of training or orientation about infection prevention and control for example Provide information on the selection and use of PPE in healthcare settings and Practice how to safely remove PPE
1. Yes
2. No 3. Don't know

9) Do you think that all staff in your unit are following promptly infection control policies, rules, and guidelines?

1. Yes agree 2. Don't know 3. No, did not agree

10) At your institution, do you have an active infection control team?
1. Yes
2. No 3. Don't know

11) Do you have an emerging infectious disease taskforce or dealing with outbreaks such as Covide 19?
1. Yes
2. No 3. Don't know

Do you think your hospital is prepared for any infection outbreak?

1. Yes agree 2. Don't know 3. No, did not agree

13) Is your hospital is enrolled in national surveillance system
1. Yes
2. No 3. Don't know

14) Do you have a list of reportable infectious agents available in your unit and accessible to all staff?
1. Yes
2. No 3. Don't know

15) Which infections are reported to $\mathrm{MOH}$ (ministry of health)?

1. All healthcare associated infections

2. All infections (both hospital and community acquired)

\section{Don't know}

16) In your institution, is there known turnaround time of laboratory results of the reportable infectious agents?
1. Yes
2. No 3. Don't know

17) Do you think that all staff can differentiate between different isolation protocols such as droplets or contact?
1. Yes
2. No 3. Don't know 
18) what reporting system in your hospital

1. Electronic surveillance

2. Paper version

3. Telephone communication

19) In your opinion, what is the effective reporting system for reporting infectious agents:

1. Electronic surveillance system

2. Paper version

3. Telephone communication

20) Do you agree that surveillance tool used in your institution is effective to prevent or control infection

1. Yes agree 2. Don't know 3. No, did not agree

21) In your opinion, what is the cause(s) of outbreaks?
1. Breaching infection control policies, rules, and guidelines

2. No clear infection control policies, rules, and guidelines

3. Carelessness of healthcare workers

4. Shortage of appropriate personnel protective equipment

5. Infection control infrastructures do not exist

22) Factors that contribute to the spread of infection in the hospital:

1. Lack and shortage of staff

2. No infection control training program

3. No resources to fulfill the infection control requirements and needs

4. No infection control on-call 